\section{Insult thwarted 1934 bid to raise profile of Indian science}

[NEW DELHI] Ill-tempered remarks by an unnamed British professor at the Indian Institute of Science in Bangalore in the 1930s about the motivation of scientists fleeing Hitler's Germany may have deprived India of a "golden opportunity" to boost its world status as a scientific nation.

The remarks were made in a lecture at a time when Max Born and other scientists were considering emigration to India - then under British rule - to take up faculty positions at the invitation of the late Nobel prizewinner C. V. Raman, who had just become the institute's first Indian director. (Earlier directors were all British.)

Others whom Raman hoped to attract included the physicists Erwin Schrödinger, Rudolf Peierls and Hans Bethe, and the chemist Georg von Hevesy. Born's interest has been recorded by Sivraj Ramaseshan, Raman's nephew and biographer, and editor of Current Science, published by the Indian Academy of Sciences. In a recent issue of the journal, Ramaseshan reveals the contents of a letter drafted by Born in reply to Raman's job offer.

In 1934, Raman offered Born a full professorship at the institute. He also invited him to share the directorship of the physics department at a "much higher" salary than Born was receiving as a lecturer at the University of Cambridge. "I have considered [the offer] carefully," Born said in his reply. But he suggested that he "could decide better" if he had "the opportunity of visiting your country, giving lectures for some months".

Raman created an extraordinary visiting chair, and Born went to Bangalore with his wife Hedi. According to Ramaseshan, both soon overcame their doubts about educating their children in India. Born found his students at the Indian Institute of Science intelligent and his lectures were well received. Urged on by Ernest Rutherford, chairman of the institute's selection committee, Born accepted Raman's original offer.

But Raman's delight was to be short lived. According to Ramaseshan, at a meeting organized to welcome the German scientist to the institute, a little known professor referred disparagingly to Born as someone "who was rejected by his own country, a renegade and therefore a second-rate scientist unfit to be part of the faculty, much less to be the head of the department of physics".

"After this public insult Born could not possibly accept Raman's offer," says Ramaseshan. Raman's hopes of getting the other scientists who had expressed an interest in coming to India were also dashed. "India, I feel, missed an incredible golden opportunity," says Ramaseshan. K.S. Jayaraman

\title{
Korean science ministry gets promised upgrade..
}

[TOKYO] South Korea's recently elected president, Kim Dae-jung, is living up to a preelection promise to strengthen the administration of science and technology. Despite political difficulties in establishing his new administration, he has upgraded the status of

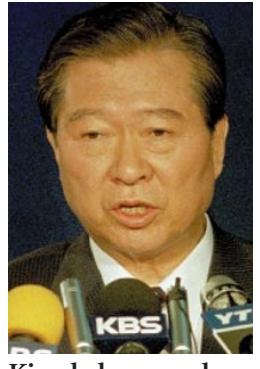
Kim: beleaguered but backing science. the Ministry of Science and Technology (MOST), and last week appointed a powerful politician to head the ministry.

Observers of Korean science policy have long argued that MOST lacks the power needed to fulfil its responsibility for coordinating science and technology policy across all ministries. Like Japan's Science and Technology Agency, MOST is more of an 'agency' than a true ministry. It is also surrounded by powerful ministries, such as that of trade and industry, with their own agendas for science and technology.

In 1993 the administration of former president Kim Young-sam talked of restructuring the government and strengthening the administration of science and technology (see Nature 364, 377; 1993), but nothing was done. In contrast, even before his inauguration in late February, Kim Dae-jung pushed through the National Assembly a bill that included upgrading MOST to a full ministry.

He even talked of appointing a deputy prime minister of science and technology, alongside the deputies for economic planning and unification. This would have raised MOST to the highest level of government. But in the end the positions of deputy prime minister were removed in the downsizing and reorganization of government.

In another show of support for science and technology, a few weeks before his inauguration, Kim visited the Korea Institute of Science and Technology (KIST), the country's longest-standing government institute for science and technology, and promised to raise the status of scientists in Korean society.

In line with strengthening MOST, Kim has appointed a powerful politician to head the ministry. The new minister, Kang Changhee, is secretary-general of the United Liberal Democrats (ULD) party, the conservative coalition partner of Kim's administration.

Kim made this and other cabinet appointments - despite a deadlock with the majority opposition party about his nomination of his conservative ally, Kim Jong-Pil, honorary president of the ULD, as prime minister — by persuading the outgoing prime minister to propose the new cabinet members.

Some scientists at KIST had been hoping that one of the institute's former presidents might head the new ministry. Nevertheless, one KIST scientist comments that, as a politician, Kang may be a more effective head of the ministry than any scientist. Kang, a graduate and former professor of the Korea Military Academy, headed a national assembly committee on communications and science in 1996, and has been involved in the development of science and technology policy.

With Korea still suffering a severe economic crisis, however, Kang faces an uphill task in strengthening science and technology at a time when government budgets have been cut and their purchasing power for importing scientific equipment and reagents, and for recruiting overseas personnel, have been halved because of the collapse of the won.

DavidSwinbanks

\section{...as overstretched universities face bankruptcy}

[TOKYO] The economic crisis

in South Korea has left several universities facing large debts as they struggle to pay back loans and leases for new facilities and high-tech equipment, according to a report in the Korean media.

The private Dankook University is said to be the first educational institution in Korea to go under, declaring bankruptcy last Saturday (7 March). Dankook was said to have been unable to pay rising interest rates on huge loans taken out to build a campus on the outskirts of Seoul and a medical school in Chonan in South

Chunchong Province.

Dollar-based repayments on loans have risen in recent months by up to 60 per cent, or 100 billion won ( $\$ 62.5$ million), because of the collapse in the value of the won. A report in the Korea Herald speculates that as many as ten universities may be on the verge of collapse.
Universities that have recently established medical schools and leased expensive medical equipment from overseas appear to have been hardest hit. Their problems are compounded by a reduction in subsidies because of cuts in the government's budget required by the bail-out of Korea led by the International Monetary Fund, and the growing numbers of students unable to pay fees in the economic crisis. D.S. 